\title{
TURISMO RURAL Y MEDIO AMBIENTE
}

\author{
José VILLANUEVA
}

Instituto de Educación Secundaria, Mixto 15, Zaragoza

Resumen: Existen interconexiones múltiples entre el hombre y el medio ambiente y la modalidad turística que intenta que las relaciones sean lo más "ecológicas" posibles entre ambos, es el ecoturismo. El turismo en contacto con la naturaleza se impone. Contribuye a la consecución y mantenimiento de un desarrollo viable a la vez que ayuda a regenerar el espacio rural conservando su propia personalidad. Hace ya una década que se empezó a difundir esta fórmula de turismo rural, con apoyos económicos de las diversas administraciones. El Alto Sobrarbe oriental, en pleno Pirineo aragonés, con abundantes recursos naturales y culturales, es un área en la que ha calado la idea de viviendas de turismo rural y los resultados positivos están siendo ya visibles. Se rehabilita el patrimonio cultural, los núcleos urbanos vuelven a recuperar cierta actividad y los censos de población no sólo han detenido su descenso sino que apuntan un ligero incremento. En suma el turismo rural es una pieza clave para conseguir la armonía entre la población rural y la urbana, y de ambas con el entorno natural.

Palabras clave: Ecoturismo, viviendas de turismo rural, pluriactividad, rendimiento sostenible, progreso.

Abstract: There are numerous interconections between man and the environment, and the kind of tourism which attempst to make the relations between the two as "ecological" as possible is ecotourism. Turism in contact with nature prevails. It contributes to the achievement and maintenance of viable development at the same time as it helps to generate the rural space by conserving its individual personality. A decade has already passed since this formula or rural tourism began to be spread around, with financial support from various administrations. The Alto Sobrarbe Oriental (High Eastern Sobrarbe), in the heart of the Aragonese Pyrenees, with abundant natural and cultural resources, is an area in which the idea of rural tourist accommodation has penetrated and the positive results are already becoming visible. The cultural heritage is refurbished, the urban nuclei revert to a state of certain activity and not only has the descent in the population censuses come to a halt but a slight 
increase is recorded. In summary, rural tourism is a key to achieving harmony between the rural and urban population, and between both populations and the natural surroundings.

Key words: Ecotourism, rural tourist accommodation, pluriactivity, sustainable yield, progress.

\section{INTRODUCCION}

En el presente trabajo se va a exponer la relación existente entre el Medio Ambiente y el Turismo Rural. El medio ambiente está de moda y la práctica de esta modalidad de turismo en los espacios rurales resurge con fuerza entre una población cada vez más urbana.

Son cuatro las partes en las que hemos dividido el trabajo: a) definición de los conceptos Medio Ambiente y Turismo Rural; b) importancia de la planificación rural para la implantación de esta modalidad de turismo; c) la fuerza del Turismo Rural como una solución, válida y aplicable en algunas áreas del mundo rural, para reconvertir el campo sin que deje de ser gestionado por el agricultor o ganadero, que siempre ha evitado que el medio natural pudiera desaparecer con el uso; y para terminar, d) ventajas e inconvenientes del agroturismo en la comarca aragonesa del Sobrarbe.

El Medio Ambiente se ha convertido en una preocupación social, política, económica y también educativa. Los movimientos ecologistas, las asociaciones en defensa de la naturaleza y las diferentes administraciones, tanto centrales como autonómicas, sienten una gran preocupación por el Medio Ambiente. Las empresas elaboran y sacan a la venta "productos verdes" con su distintivo de calidad, y en el nuevo sistema educativo español en fase de implantación, se contempla ampliamente el Medio Ambiente.

Cualquier postura extremista es concomitante con su contraria y ambas además de utópicas, nada fiables, poco reales y por tanto desechables. Progreso y conservación, desarrollo y medio ambiente no son conceptos antagónicos, son más bien complementarios y en última instancia se refuerzan mutuamente. Hemos de tender hacia lo que se ha dado en denominar un desarrollo viable en el que los conceptos de conservación, preservación y aprovechamiento se aplican a un mismo espacio.

La Meta Ambiental de la Carta de Belgrado de 1975 hablaba de "mejorar las relaciones ecológicas, incluyendo las del hombre con la naturaleza y las de los hombres entre sí". Hay que tener siempre presente al hombre, como protagonista 
fundamental de toda actuación en el planeta Tierra. Ya que la mirada al futuro nos depara posibilidades y no determinismos, podemos pensar en la eficacia de la participación activa del hombre en la mejora del medio ambiente.

El Medio Ambiente ha entrado a formar parte de los modelos económicos en su conjunto. El mundo, dada la distribución y escasez de recursos naturales, está tomando conciencia de que es preciso administrar mejor el patrimonio medioambiental de la humanidad, sobre todo en una época como la nuestra en la que priman el desarrollo y el crecimiento, que muchas veces se constituye como enemigo del medio ambiente.

La noción de genre de vie (modo de vida) acuñada por Vidal de la Blache, y el concepto de nivel de vida, no ha perdido valor, pero hoy se habla más de Calidad de vida. Independientemente de que se quiera dar una mayor o menor relevancia a las posturas humanísticas o neopositivistas, no cabe duda de que la Calidad de vida va unida a la existencia de un medio ambiente no deteriorado.

Problemas ambientales son la capa de ozono, la contaminación, etc. pero también la desaparición de algunas actividades laborales o la presión demográfica. Los factores físicos, sociales y culturales conforman una estructura superior que denominamos Medio Ambiente. Citar el Medio Ambiente no es sinónimo de nombrar naturaleza como se suele creer, pues nos olvidamos del protagonista fundamental, el hombre, verdadero ser superior capaz de mantener el equilibrio ecológico o de destruirlo. Hombre o Medio Ambiente, Medio Ambiente u Hombre, independientemente del orden, lo cierto es que no se entienden uno sin el otro, formándose entre ambos un sistema de interconexiones múltiples o biocenóticas. Cabe asumir como propia la definición que da Pierre George de la Geografía, al definirla como "la ciencia del medio ambiente humano". De ahí que la geografía tenga mucho que decir en cualquier planificación y actuación sobre el medio natural, la consecución y mantenimiento de un rendimiento sostenible o lo que viene a resultar lo mismo, la búsqueda de un uso múltiple del espacio natural en el que desaparezca el papel preponderante otorgado al medio, como proveedor de recursos para mantener el excesivo consumo material en el que estamos inmersos.

La vida del hombre sobre la tierra ha supuesto, con mayor o menor intensidad, la realización de una serie de actividades que en gran medida han ido devorando el medio natural. El ser humano es un gran consumidor de recursos. Fundamentalmente, unida a la industrialización acaecida en los dos últimos siglos, la acción antrópica se ha dejado sentir tanto en los bosques, como en la atmósfera, aguas, etc. hasta el punto que se ha llegado a una situación límite, de crisis profunda, lo que podríamos denominar punto de histéresis o de máxima inestabilidad, del que debemos procurar que evolucione hacia un nuevo estado de equilibrio lo antes posible. 
Si bien la mayor parte de las actuaciones humanas han supuesto la desestabilización de muchos ecosistemas, por implantaciones fabriles, y la construcción de infraestructuras de comunicación y transportes. Ahí están por ejemplo la mayoría de las autopistas españolas trazadas sin previos estudios de impacto ambiental, y las ocupaciones masivas de suelo en el litoral mediterráneo que han producido grandes desastres ecológicos, afirmación tajante y constatable a la vista sin necesidad de profundizar más. $Y$ es que las actividades relacionadas con el turismo se han apoyado siempre en los dualismo sol-nieve o costa-montaña, irrumpiendo, sangrando y destruyendo entornos. Sobran experiencias y ejemplos en nuestro país al respecto. Urbanizaciones, complejos residenciales, edificios de apartamentos, han ido conformando un cinturón litoral de carácter urbano, la ansiada "Primera línea de costa", a la que en ciertos núcleos se han unido un segundo y tercer cinturón, siguiendo los necesarios viales construidos dado el aumento de tráfico padecido y la fuerte demanda de alojamientos de escasa calidad, centrada en las décadas de los sesenta y setenta, con un nulo control urbanístico.

En los momentos actuales, bien por conciencia ciudadana o por la misma espiral de la vida, el sector hotelero precisa una gran reconversión. Si no se cambia el estado de los establecimientos, tan deteriorados, y se oferta una verdadera calidad, el cierre definitivo es seguro. Lo cierto es que la transformación en el sector debe ser total y una de las alternativas que resurgen con fuerza por diversos motivos tanto económicos y sociales, como ambientales es el denominado Turismo Rural. A la etapa vivida hasta la fecha de explosión turística, debe seguir otra que sea fruto de una planificación en la que se defina claramente lo que se desea, si volver sobre las mismas estructuras o adoptar fórmulas y formas nuevas.

Son muchos los detractores de las ventajas del turismo. Es más, algunos sólo ven inconvenientes y comparan la actividad turística con una apisonadora capaz de arrasar un área desde un punto de vista financiero, ecológico y social. Se habla del mito que supone el turismo tomado como estrategia de desarrollo, generador de empleo y riqueza, vía de comunicación, etc. cuando lo único que verdaderamente consigue el turismo que hemos vivido es un cambio brutal desde un plano cultural, social y ambiental. Sessa cita hasta nueve cours du tourisme ${ }^{1}$, como su carácter estacionario, y fundamentalmente la implícita demanda de acciones contra la naturaleza, desde la actuación de las grandes inmobiliarias hasta las incursiones domésticas, de índole individual. El problema de la vulnerabilidad del turismo, fruto de su condición de sistema abierto, debe y puede subsanarse con una reorientación hacia nuevos enfoques, fundamentalmente hacia prácticas de mayor contenido cultural. El mito se habrá convertido así en ciencia experimental.

1 SESSA, Alberto (1989): La science des systemes pour les plans regionaux de developpement touristique. Centro des Hautes Etudes Touristiques. Aix-en-Provence, pp. 24. 
El fenómeno turístico es una realidad bastante compleja puesto que abarca campos y dimensiones muy diferentes. La incidencia positiva o negativa de la actividad turística sobre una sociedad variará según se conjuguen los intereses económicos, socio-políticos y medioambientales. Además, admitir solamente el papel destructor del turismo es obviar la existencia de otras variables beneficiosas. Y es que bajo este nombre, turismo, se engloban múltiples variantes, desde el llamado turismo hotelero al turismo residencial por citar algunos, si bien ante esa generalidad maligna que se le achaca desde ciertos sectores de la sociedad, bueno será contestar con otra generalidad benigna, como es la de afirmar que el deterioro natural va en contra de cualquier motivación turística. Por lo tanto, el sistema turístico está relacionado directamente con el sistema ecológico del cual depende y, agotado éste, desaparece aquél. Un medio ambiente preservado constituye el principal valor de un área turística, siendo uno de los atractivos fundamentales cuando se planean unas vacaciones.

Así pues, dentro de todas las variantes posibles, apostamos por el Ecoturismo, turismo ecológico o agroturismo. Es decir, aquel turismo que utiliza como alojamiento dependencias de las casas en las que habitan los lugareños, y en el que por tanto desaparece la masividad de los macrohoteles y se establece una atención y un trato más humano entre visitantes y visitados.

El Turismo como actividad surge ya en el siglo XIX. En las sociedades postindustriales, con el aumento del tiempo libre, el Turismo ha pasado, junto con la recreación, a convertirse en una necesidad; pero si evidente es esta última afirmación no lo es menos la necesidad de preservar el medio ambiente, de ahí que se intente conjugar una y otra, y el turismo rural es una alternativa viable.

Bajo la denominación de turismo rural no se esconde una noción nueva; estamos ante un concepto múltiple: diferente, integrado, verde, interior, endógeno, cultural, doméstico, alternativo, polivalente y abierto. Dado el número de características de este tipo de turismo, todas positivas, se diría que estamos ante una panacea, y si bien no es así, pues no remedia por sí sola los males sociales, sí estamos ante una estrategia válida que permite actuaciones locales positivas incardinadas dentro de planificaciones globales.

Que el turismo costero y masivo, efectuado hasta la fecha en España, ha sido demoledor, devastador, ha traido consigo la inflación y, con ella, la especulación del suelo, no lo puede negar nadie, es una realidad con mayúsculas. El turismo así entendido, no es el pasaporte para el desarrollo. Los políticos, urbanizadores y promotores son los grandes beneficiarios y el resto de la sociedad en su conjunto la gran perjudicada cultural y económicamente hablando. El hecho turístico español de las tres últimas décadas, desde la perspectiva de la oferta se ha basado en sol, playa y 
unos precios irrisorios para la capacidad económica de los turistas potenciales. Desde la perspectiva de la demanda, los visitantes no eran muy exigentes dado que la comprobación in situ del retraso secular en el que estaba inmerso el pais que visitaban, les colmaba de satisfacción y elevaba su ego al constatar su superioridad. La sobreexplotación turística fue abrumadora y esquilmante. Según el profesor Díaz Alvárez el siguiente dato es ya de por si significativo: "Desde 1960 a 1970 la llegada anual de extranjeros a España supuso un incremento, en términos absolutos, de 18 millones de visitantes, y un incremento relativo de casi el 400 por $100^{\prime \prime}$.

El turismo rural en esencia no es masivo y su implantación ha de ser siempre, para no perder su espíritu, a escala reducida, tal como veremos más adelante. Si bien no estará de más no olvidar la lección aprendida de lo sucedido con las zonas costeras.

Llegados a este punto, cabe hacerse la siguiente pregunta: ¿Sigue existiendo el antagonismo entre medio rural y urbano? En la actualidad este antagonismo ha desaparecido. Se habla de la integración del mundo rural en una sociedad global de forma y manera que el espacio rural pierde su personalidad y se desintegra al depender de decisiones situadas en otra escala. Así la fijación de precios, implantaciones comerciales, etc., se encuentra al servicio de una parte de los ciudadanos y de las empresas.

Para que el espacio rural no pierda su personalidad se tiende a incorporarlo al sistema global, no a través de su absorción, sino mediante fusión, es decir, conservando sus propias peculiaridades y relacionándolo con el resto de espacios ya sean urbanos, industriales,... El turismo rural aparece así como elemento aglutinador, de manera que esta modalidad deja de ser una mera actividad económica para desempeñar un papel fundamental en el plano social. Es preciso que la sociedad compatibilice los progresos técnicos y los valores socioculturales del medio rural, y para ello el turismo rural ha de servir de vehículo de comunicación entre el hombre y el entorno natural y sociocultural; permitiendo el entendimiento entre el hombre que reside en la ciudad y el que reside en un núcleo urbano de menor entidad.

El nivel de progreso social será tanto mayor cuanto más integrada se encuentra la sociedad interiormente y en relación con el medio ambiente; y una pieza clave para conseguir la armonía entre la población rural y la urbana, y de ambas con el entorno natural, es el turismo rural.

Sin embargo, es conveniente afirmar que plantear el turismo como la Solución Universal es tener una equivocada visión de futuro. Es necesaria la pluriactividad como factor de mantenimiento de la población, sin ella proponernos la revitalización de una zona como objetivo específico, adolecería de sentido. Por contra, contando con la población, están plenamente justificados los objetivos operativos de partir de una base 
ganadera y complementarla con un turismo artesanal, integrador y desmasificador. Es decir, toda estrategia, para que no falle ya en la teoría, requiere una planificación "con" la población autóctona. Su toma de conciencia favorable es imprescindible. A partir de aquí, bien planificado, el turismo puede suponer un factor de revitalización sociocultural y de dinamización económica. Es preciso subrayar lo de "buena planificación" para que no se vea abocado al fracaso el conjunto de medidas a tomar, entrando así en el apartado siguiente sin olvidarnos de la importancia capital que tiene, para poder establecer unas estrategias correctas, el saber lo que se quiere conseguir.

\section{ESPACIO ¿AGRARIO O TURISTICO?}

Si hoy por hoy resulta inconcebible cualquier tipo de actividad económica sin una planificación previa, es igualmente inconcebible que ésta se haga sin tener en cuenta los posibles efectos medioambientales que pudieran derivarse de ella. Es preciso por tanto que el paradigma medioambiental pase a ser el coordinador y aglutinador de cualquier política territorial tanto en el plano de las relaciones del hombre y la tierra, como en el plano de la organización espacial. Se debe considerar como una materia transversal, interdisciplinar e integradora a la hora de trabajar sobre un área determinada sea urbana o rural, litoral o montañosa.

¿Cualquier espacio rural sirve para implantar este tipo de modalidad turística? Desde luego que no, hacen falta una serie de condiciones y recursos que no tienen todas las áreas y que son imprescindibles, ya sean atractivos naturales, culturales, de infraestructura, etc. Ni qué decir tiene que el espacio pirenaico es inmejorable para este tipo de actividad pero es fundamental una buena política de ordenación territorial. Por una parte, si la montaña se percibe como un filón a explotar con fines comerciales o económicos, dejará de ser montaña, y si se presenta como un espacio a administrar por funcionarios con fines ecológicos, pasará de ser una montaña habitada a ser una plantación.

Cada una de las cadenas montañosas que existen en el planeta por mucha historia geológica común que posean, en realidad son un complejo singular, con grandes diferencias entre ellas, fruto de una evolución natural distinta y de una actuación antrópica desigual. En concreto y dado que el estudio lo vamos a realizar sobre una parte del Pirineo, habrá que recapacitar y reflexionar sobre este espacio pirenaico y decidir lo que queremos que sea: un desierto, un bosque industrial, un "segundo litoral" o un lugar donde la gente siga viviendo y a la vez esté integrada en la sociedad de fines del siglo XX. Si se opta porque la montaña siga habitada habrá que evitar que la gente que aún vive se marche y para esto es conveniente tomar una serie de medidas 
tales como: ayuda a la agricultura, promoción de la artesanía, mantenimiento de los servicios públicos y, lo que trataremos más en profundidad, fomentar el turismo rural. Esta última salida aparece como el motor revitalizador de la economía de montaña junto con el mantenimiento y reestructuración de actividades tradicionales. Así pues ante la pregunta que sirve de titular a este apartado, la respuesta no se decanta por la actividad primaria o la terciaria en exclusiva. En la medida de lo posible, la contestación más coherente es un espacio mixto en el que a las tareas tradicionales se incorporen algunos servicios.

Un turismo entendido, de manera racional y nunca como invasión, es un poderoso instrumento para llevar a cabo una política de montaña que se preocupe de: asegurar a las poblaciones un nivel de vida digno; utilizar sus posibilidades productoras, carne, piel, etc. y de organizar la ocupación del espacio.

Antes de pasar a profundizar en una correcta planificación bueno será citar una serie de principios que deben de estar siempre presentes, y para ello baste con citar lo que Manuel Valenzuela ${ }^{2}$ llama líneas de acción a seguir siempre desde una perspectiva territorial integradora, y que las resume así:

- Salvaguardar los espacios naturales de calidad y suelo fértil a la penetración de otros usos de carácter disperso y graves efectos deteriorantes.

- Habilitar para el suelo no urbanizable calificaciones e instrumentos de gestión equivalentes a las usadas para el suelo edificable, que permitan su supervivencia sin anular su rentabilidad económica.

- Potenciar prudentemente los procesos de desarrollo endógeno ligados a los recursos no agrarios, de los que formará parte la promoción del Turismo Rural.

- Estimular a través del planeamiento la aparición de condiciones atractivas para que la estancia de turistas encuentre un ambiente grato y cómodo.

- Garantizar la conservación de los elementos físicos del entorno, patrimonio y espacios verdes.

- Asegurar la conservación de la arquitectura popular, incorporando los elementos actuales y dotándola paralelamente de alternativas de uso turístico-residenciales así como de cauces de financiación y gestión.

2 VALENZUELA RUBIO, Manuel (1988): "El turismo rural, la vuelta a la tierra de las sociedades urbanas". En Revista Referencias, 4, Ministerio de Cultura, Madrid, pp. 33 
Cualquier iniciativa de implantación del turismo rural, tanto a nivel comarcal como subcomarcal, debe de contar siempre con un estudio previo de viabilidad social y económica; el impacto ambiental es una materia transversal que estará presente en cualquier actividad que se vaya a llevar a cabo. Dicho estudio contará con al menos tres grandes bloques que podríamos denominar: natural, humano y turístico.

En el apartado natural se realizará un análisis del entorno físico: Unidades morfoestructurales, hidrografía, biogeografía y climatología con las posibles variaciones estacionales, siempre orientado a explicar su originalidad y atracción.

En el apartado humano se incidirá especialmente en la estructura demográfica y socioeconómica, así como en la distribución comarcal y en la importancia de las actividades tradicionales ya sean agrarias, forestales o ganaderas, en tanto en cuanto tengan algo que ver con el turismo.

En el apartado turístico se hará una primera subdivisión entre Oferta Turística y Propuestas de Ordenación Territorial; dentro de la Oferta y partiendo de una premisa cierta, "...de gustos no hay nada escrito...", se considerará todo aquello que pueda resultar potencialmente atractivo, ya sea natural, cultural o etnológico y la infraestructura existente, hotelera, viaria y de servicios comerciales y asistenciales. Dentro de las propuestas incluiremos desde los objetivos hasta la valoración de la capacidad de acogida.

Conocer, evaluar y después elegir las fórmulas más adecuadas a cada espacio geográfico es nuestro método de trabajo. Así se estudian los recursos y también las necesidades o carencias para realizar acciones que nos conduzcan hacia un desarrollo ecológicamente racional. No estamos abogando por otra vía distinta a la planificación; ésta ha de ser previa a cualquier realización e implica la plasmación por escrito de unos objetivos a alcanzar a través de las actividades que se apoyan en la diversidad de recursos: humanos, materiales y económicos de que disponen las comarcas, partiendo así de abajo a arriba, de lo próximo a lo lejano, de la realidad a los despachos. En una palabra, del análisis a la síntesis, cual si de un método empirista se tratase.

Un rasgo del espacio geográfico es la heterogeneidad, surgida por unas condiciones naturales de por sí muy diversas y por la diferente intervención humana. Respecto de la organización del espacio Labasse ${ }^{3}$ nos dice: "...la organización tiene por finalidad última abrir considerablemente nuestro universo material y espiritual al progreso y a la esperanza.". De ahí se deduce que se deban prestar mayor atención a

3 LABASSE, J.(1973): La organización del espacio. Instituto de Estudios de Administración Local, Madrid. pp. 735. 
cuestiones meramente cualitativas. Por otra lado, el verdadero planificador necesita conocer el espacio sobre el que se pretende actuar. Esto puede parecer superfluo, pero no sobrará mientras se siga administrando y gestionando a distancia, bajo modelos prefabricados. El conocimiento del lugar es previo y punto de partida para realizar cualquier acción. Además se deben considerar los puntos de vista del técnico y del intelectual, ya que el uno comprende los problemas en su extensión conceptual y el otro en su intensidad vivida; el pensamiento, sea intuitivo o lógico, y el reflexionar sobre los aspectos y los concepto son dos vías concurrentes e inseparables, del análisis y de la planificación.

La racionalidad en el uso de los recursos, la participación de la población que garantice una autonomía sin manipulaciones y un alto grado de solidaridad son dimensiones básicas para que se de una evolución social. Hay que añadir la cuestión sicológica, poco tenida en cuenta y que tiene un peso específico importante, pues si la economía mueve la historia también cuentan las ilusiones y amarguras de la gente. $Y$ es que no debemos confundir lo que es un mero crecimiento con un verdadero avance, el desarrollo, que incluye cambios hacia un auténtico progreso.

\section{TURISMO RURAL}

Escribir sobre el turismo rural en 1994 hace que sea necesario afirmar cómo el paso inexorable del tiempo y, con él, el devenir de los acontecimientos, está dando la razón a aquellos que tan sólo hace nueve años -en 1985- se animaron a promover esta modalidad turística, en Taramundi (Asturias), en la comarca de la Vera (Extremadura) y en Gúdar y el Bajo Maestrazgo (Aragón). Esta iniciativa fue secundada enseguida en las también comarcas aragonesas de Ribagorza y la que nos ocupará en el apartado siguiente, el Sobrarbe. La Administración, para promover esta modalidad, obligó a formar asociaciones o cooperativas, como DITASA en Asturias, y TURAL, en Aragón, que son las receptoras de las ayudas económicas que proporciona para la implantación de estas actividades turísticas.

A las antiguas "casas de labranza" en tiempos del Ministerio de Información y Turismo, allá por los años sesenta y setenta, han sucedido las denominadas "viviendas de turjsmo rural" promovidas por la Secretaría de Estado de Turismo, en principio, y, a partir de la mitad de la década de los ochenta, con las transferencias relativas al turismo, cedidas a las comunidades autónomas, estas viviendas han sido favorecidas por las respectivas consejerías, normalmente incluidas en los Departamentos de Industria, Comercio y Turismo, con ayudas a veces importantes. 
A las ayudas de los gobiernos autonómicos hay que unir las recibidas vía fondos del FEDER, aportados por la Comunidad Europea, destinados a programas de desarrollo como el "Leader". Así han ido surgiendo nuevas comarcas que ponen todos sus esfuerzos en promover este tipo de turismo verde o rural, es el caso de El Bierzo o los Ancares en León, o la Asociación de Turismo Rural de Gerona; en el presente año 1994 son varias las comunidades autónomas que en sus directrices del sector turístico tienen muy presente esta modalidad a la que auguran un buen futuro destacando el caso de Navarra, La Rioja, Galicia, Pais Vasco, Aragón por descontado y hasta por chocante que pueda parecer, el gobierno Balear, oferta viviendas rurales en la isla de Mallorca.

Sabido de todos es que desde una perspectiva regional, los interesados se centran en sus propios límites geográficos y la mayoría de las comunidades autónomas intentan vertebrar su territorio con el ánimo de conseguir un mayor equilibrio del mismo y evitar las abismales diferencias entre el mundo rural y el urbano, y para ello están considerando el turismo rural como un verdadero instrumento que va a facilitar el desarrollo en las zonas más desfavorecidas. De ahí que esta forma de turismo cada vez se vea más favorecida pues se considera que es causa de una serie de efectos positivos muy beneficiosos económica y socialmente, que revierten directamente sobre los espacios rurales, apareciendo un incremento y diversificación de las actividades en el mundo rural, tanto en el plano hotelero, como en artesanía, comercio y sobre todo en la construcción, consiguiendo así la rehabilitación del patrimonio inmobiliario.

El Manifiesto del Turismo en Espacio Rural propuesto por la Asociación TER (Turismo en Espacio Rural), en 1972, ya afirmaba que el turismo en espacio rural iba a ser la riqueza campesina de mañana. "Favoreciendo un mejor conocimiento recíproco entre población rural y urbana, contribuirá a la elaboración de un estilo de vida adaptado a la evolución del mundo moderno y especialmente de la civilización del ocio". Pero hay que subrayar que los efectos positivos, tanto sociales y económicos, como demográficos, producidos por la implantación del turismo rural, se deben a que en la actuación y desarrollo de los programas se ha contado con la población residente realizándose una gestión local. En estos momentos una valoración de conjunto de las repercusiones de la apuesta por el turismo verde o rural permite afirmar que la desolación y abandono rural de los años sesenta-setenta, no sólo ha desaparecido en los espacios rurales donde se ha actuado, sino que se han alcanzado unas cotas de bienestar muy similares a las urbanas y en ocasiones hasta superiores, contando siempre con las peculiaridades de cada área.

El Ecoturismo, el turismo en contacto con la naturaleza, se impone, es una necesidad, y son muchos los países que han apostado de forma decidida por esta fórmula, no ya sólo en el continente europeo, donde Austria, Italia o la misma Francia hace años que la pusieron en marcha, sino también en el continente americano con la 
puesta en funcionamiento del proyecto "Paseo Pantera" con un área de actuación en todo el istmo centroamericano, siendo uno de sus objetivos específicamente el desarrollo del ecoturismo regional.

Está acabando el turismo en el que el visitante tenía un carácter pasivo. El usuario del turismo rural es un hombre urbano deseoso de espacio y de tranquilidad, aspecto que no se debe confundir con inactividad; así, hoy por hoy, va a primar, porque así se demanda, un tipo de turismo cultural, deportivo e incluso educativo, en el que el alojamiento debe colocarse en su justo sitio. La pernoctación es un medio y no un único fin. Es preciso pensar en un producto turístico completo, y además, a ser posible, con marca de calidad, en el que figure además del alojamiento la alimentación y sobre todo la recreación, por supuesto activa, en la que exista y prime una comunicación entre visitantes y visitados, respetando el medio sobre el que se relacionan y conviven, de forma natural y auténtica. La modalidad de pernoctación en viviendas de turismo rural lleva implícito el contacto y diálogo con el montañés, o lo que es lo mismo, posibilita de hecho el conocimiento de una forma de vida agroganadera donde el ritmo de vida no viene marcado por el reloj de la muñeca, sino por el discurrir del medio en el que se vive.

\section{ALTO SOBRARBE ORIENTAL}

En el presente trabajo, queremos dejar claro desde el primer momento que estamos a favor del agroturismo, como una variedad de la actividad turística completamente compatible con el respeto al medio ambiente, y en esa línea presentamos la subcomarca aragonesa del Alto Sobrarbe Oriental como marco de referencia a seguir por cualquier otra comarca o área interesada en el Ecoturismo.

La comarca del Sobrarbe, y por ende el Alto Sobrarbe Oriental, lleva todos los visos de convertirse en una especie de "comarca isla"4, un espacio habitado rodeado de Parques Nacionales y pantanos; así a la atracción propia del Alto Cinca, se une la resultante de ser entrada a los mejores espacios naturales y de mayores dimensiones de toda la Cordillera.

En el norte de la comunidad autónoma de Aragón se encuentran las históricas y legendarias tierras del Sobrarbe; y dentro de esta vasta y agreste comarca montañosa, el Alto Sobrarbe Oriental se sitúa en plena cadena pirenaica, entre la Ribagorza al

4 VILLANUEVA ZARAZAGA, J.(1991): Sustitución del sistema agrario tradicional por actividades modernas en el Alto Sobrarbe Oriental: el turismo. Memoria de Licenciatura, Universidad de Zaragoza, $245 \mathrm{p}$. 
Este, la cresta fronteriza al Norte y el Parque Nacional de Ordesa y Monte Perdido al Oeste. Comprende la "bal de Chistau", Bielsa, las tierras de Laspuña y el valle de Puértolas hasta L'Aínsa, que representan un $4.8 \%$ del territorio oscense y tan solo un $1^{\prime} 07 \%$ del total de la población provincial; con una de las rentas per capita más bajas a nivel regional.

En el interior de la cadena montañosa, donde los macizos calcáreos superan la altitud del Pirineo Axial, cuenta con marcos inmejorables desde un punto de vista ecológico que son fruto de una integración plena del hombre con su espacio natural. Aquí encontramos un creciente proceso de selvatización fruto de la extinción casi total del tejido social. Nunca ha sido el Sobrarbe una comarca densamente poblada, pero en los ochenta se llegó a los mínimos de irreversibilidad y, de no actuar pronto, y bien, la comarca como territorio organizado, transformado y utilizado por grupos humanos, dejará de existir y, con ello su principal activo actual: el Paisaje. Aquí coexisten a la vez, cual si de un milagro se tratase en los tiempos que corren, cinco planos de conciencia ambiental que Nogué ${ }^{5}$ denomina experiencia ambiental: El paisajeespectáculo del veraneante, el paisaje-mercancía como concepción pictórica, el paisaje de los campesinos con su concepción cíclica del tiempo, el paisaje vivencia del excursionista y el paisaje ambiental, digamos neorural, en el que se valora la ausencia de sonidos técnicos. Aunque en cualquier punto del Alto Cinca encontramos a la vez los cinco planos de conciencia citados anteriormente, podemos nombrar a modo de ejemplo cinco áreas en las que prima uno de ellos. Podríamos preguntarnos retóricamente: Qué añadir al valle de Pineta como paisaje espectáculo o a la imagen pictórica de los glacis de Laspuña con el telón de las peñas Montañesa y Solano, y las puntas Llerga y Suelza al fondo; al paisaje agrario de El Pueyo o la Comuna en Chistau; al paisaje experimental del excursionista en Viadós o al ambiental neorural del núcleo despoblado de Escuaín. Este Paisaje del Alto Sobrarbe es todo un lujo, que debe de preservarse para disfrutarlo y poderlo legar a las generaciones futuras tal como el montañés ha sabido transmitirlo a lo largo de los siglos. Nadie como el sobrarbés, ha sido capaz de concebir este espacio a la vez como suelo donde vivir y como herramienta para trabajar.

Así, siendo el alto Sobrarbe un área demográficamente débil con un incremento temporal fuerte, que tiene el paisaje como su principal activo económico, y para mantener unas relaciones armónicas del hombre con la naturaleza sin menoscabo de la alta calidad ambiental que hoy posee, proponemos los objetivos específicos siguientes:

\footnotetext{
5 NOGUE I FONT, J. (1992): "El paisaje existencial de cinco grupos de expriencia ambiental", en Geografía y Humanismo, de Aurora Ballesteros, Oikos-Tau, 91 p.
} 
- Mejorar las condiciones de existencia de la población rural tanto en el plano económico como en el social, facilitando la implantación de nuevas actividades y respetando su propia cultura.

- Conservar y rehabilitar el patrimonio socio-cultural.

- Iniciar acciones de regeneración y conservación ecológica; preservando la naturaleza sin menoscabo de una posible utilización racional.

- Crear lugares de acogida y recreo que posibiliten una armónica relación entre visitantes, visitados y el marco natural.

- Desarrollar modos de relacionarse con la realidad basados más en la comunicación que en la simple observación.

Los instrumentos operativos, serán muchos y muy variados, como pertenecientes a diversos campos, técnicos, económicos y legales; y todos ellos englobados en uno: el desarrollo del turismo rural.

De entrada hay que decir que el Alto Sobrarbe Oriental goza de una situación geográfica envidiable, dado que el futuro se encuentra en la Europa de las regiones, su emplazamiento fronterizo puede ser un lugar de paso en un más que posible incremento de relaciones con el resto de países europeos y, además, toda la comarca es ya hoy uno de los mejores pulmones de la Europa Occidental; un entorno de calidad, montañoso, sin polución, lejos de cualquier central nuclear. En definitiva, un medio rural en sí, pintoresco y atractivo para el urbano, al menos por cuanto de novedad y cambio de imagen le supone al habitante de la ciudad la estancia en estos parajes.

El estado actual de conservación, la diversidad y el uso racional del mismo hacen que estemos ante un paisaje privilegiado para quien tiene la posibilidad de verlo y recorrerlo. Es un verdadero escaparate natural, con variedad litológica y estructural que dan lugar a formas de relieve diferentes, desde formas kársticas a modelados glaciares. Variedad biogeográfica de alto valor científico, desde las altas cumbres a las riberas de ríos como el Cinqueta, Yaga, Barrosa y Cinca, sin contar los innumerables barrancos y arroyos que contribuyen a ensalzar el potencial hídrico con sus nada desdeñables aportes. A esto se añaden los ibones como Urdiceto o El Cao, grandes y majestuosos glaciares en épocas pasadas, con muestras visibles hoy en Posets y Monte Perdido.

No quedaría completa esta somera valoración del medio natural sin tener en cuenta las condiciones climáticas. Es preciso hablar de la luminosidad. Los días despejados son numerosos, contribuyendo el sol a dar claridad y energía a unas tierras 
de por sí vigorosas. Las precipitaciones ${ }^{6}$ son menores de lo que cabría esperar por su situación montañosa, la baja altitud a la que se encuentran las poblaciones, hace que debamos desmitificar la aureola de frío creada entorno al Pirineo y por consiguiente a estos valles. Las temperaturas estivales son suaves y los días invernales soleados, frutos de la inversión térmica que se produce con respecto a la ribera del Ebro o la Hoya de Huesca, animan a ponerse en contacto con la naturaleza.

Pasando al plano demográfico hay que decir que estos valles han estado poblados desde tiempos remotos si bien nunca han soportado una gran cantidad de población. El aislamiento ha sido una constante y una vez desaparecido en parte este problema con el acondicionamiento del Eje del Cinca, los montañeses han ido abandonando el hábitat polinuclear para concentrarse en torno a los nudos viarios. Ainsa, Escalona o la misma Bielsa, son claros ejemplos.

Al escaso número de habitantes, apenas dos mil quinientos, que equivalen a la población residente en dos bloques de casas de una gran ciudad, hay que añadir que se trata de una población regresiva hasta el censo del año 1981 y estabilizada con un cierto giro al alza en esta última década, con los problemas añadidos por su estructura desequilibrada, con mayor número de varones y un índice de envejecimiento elevado, rayando en algunos municipios los límites de la renovación generacional.

Consecuencia de los elevados movimientos migratorios padecidos, ha sido la desaparición de la organización social y económica en torno a la "Casa" como unidad de producción y de derecho sucesorio, por la ausencia de gente joven en muchas familias y por la evolución económica moderna.

La agricultura es meramente testimonial; la ganadería ha caído verticalmente, y la explotación forestal es cada vez menor por el límite ecológico altitudinal de los bosques y los abusos de antaño. Con este panorama productivo es fácil suponer el elevado nivel de insatisfacción de la población. Ninguno de los sectores laborales a los que se dedica goza de buenas perspectivas; de ahí que se busquen soluciones o alternativas distintas capaces de hacer crecer la esperanza. La pluriactividad sería la vía correcta que, por otra parte, no es algo nuevo para el montañés pues siempre ha tenido que dedicarse a trabajos varios para sacar su hacienda adelante, e incluso, a temporadas, se ha visto obligado a ir a trabajar a Francia. En la actualidad una apuesta por la dedicación al turismo rural compaginando las tareas meramente turísticas con las tradicionales agro-pastoriles es la fórmula para alcanzar mejores cotas de bienestar. El Sobrarbe aparece pues, ya en la actualidad y de cara al futuro próximo, como un espacio dedicado a satisfacer una demanda social cada vez más importante: la recreación en contacto directo con la naturaleza.

6 VILLANUEVA ZARAZAGA, J. (1991): op. cit. p. 61 
La complementación entre la agricultura y ganadería a base de la producción de pastos, así como la dedicación por parte de la población residente, hacia la obtención más o menos artesanal de productos derivados del ganado, quesos y embutidos, enfocados hacia el propio consumo y venta a los turistas, junto con una dedicación a actividades del sector servicios, restaurante, guías, etc. no sólo pueden paralizar la dinámica de huída de población de este medio rural, sino llegar a cambiar el sentido de aquélla y hacer de la acogida, temporal o definitiva, en este ámbito territorial, algo habitual. Expuestos así los argumentos, la visión prospectiva de la comarca sobrarbesa es bastante esperanzadora, pero, y he aquí el quid de la cuestión:

¿Qué capacidad de acogida puede tener el Alto Sobrarbe Oriental?

No resulta fácil la tarea de mantener la calidad de los recursos, y proporcionar al usuario una experiencia cualitativamente rica, y al receptor una rentabilidad económica y social, todo al mismo tiempo. La solución consiste en establecer lo que podríamos denominar un equilibrio dinámico, nada fácil si tenemos en cuenta la complejidad del sistema turístico.

En conjunto y sin tener en cuenta la población que todavía utiliza la prohibida acampada libre, el Alto Sobrarbe Oriental puede acoger en estos momentos un total aproximado de 4.204 visitantes, contabilizando en esa cifra las plazas de refugios de montaña y las viviendas secundarias ocupadas por cuatro personas de media, más las plazas hoteleras, camping y viviendas de turismo rural. Ello significa de entrada que estos valles pirenaicos han de soportar en algunos meses una mayor presión demográfica de la habitual pasando de una densidad de $3^{\prime} 1 \mathrm{~h} / \mathrm{Km}^{2}$ a $11^{\prime} 9 \mathrm{~h} / \mathrm{Km}^{2}$, cuando la ocupación de alojamientos es total. Es precisa una urgente ordenación territorial para evitar los deterioros paisajísticos y problemas ecológicos en general, que desvaloricen el atractivo de la comarca.

Pero es necesario profundizar más para acercarnos a la realidad. En lo relativo a los alojamientos existentes, en la actualidad la oferta asciende a un total de 313 habitaciones hoteleras, 2.274 plazas de camping y 130 habitaciones de turismo rural; a lo anterior, hay que unir las cerca de 240 viviendas secundarias y las 253 plazas repartidas en ocho refugios de alta montaña. De estos datos se puede apreciar que más de un sesenta por ciento de las plazas corresponden a un alojamiento en refugio o en tienda de campaña, apropiado solamente para época estival y ni siquiera a lo largo de toda la estación.

Por otro lado, si nos atenemos a la tasa de función turística, es decir, la relación entre la capacidad de alojamiento y la población, podemos afirmar que, hoy por hoy, los municipios de Bielsa y Puértolas ya tienen una clara función turística, ambos superan la tasa 100, en la que el número de alojamientos es igual al número de personas 
que allí viven. Labuerda con el camping ubicado en su término, tiene la tasa más elevada de todo el Alto Sobrarbe Oriental; Plan alcanza la tasa 199 con los alojamientos del camping y sin él se queda en 41'8; la menor tasa la tiene El Pueyo de Araguás con 27 '2.

En general podemos afirmar que la tasa de función turística de todo el Alto Sobrarbe Oriental, todavía no es muy elevada, 83'6, teniendo en cuenta las plazas de hotel, residencias secundarias y viviendas de turismo rural; si se contabilizan también las plazas de camping la cifra se dispara a 179.

Hay que destacar que la causa de estas cifras aparentemente elevadas, se encuentra más que en la cantidad de alojamientos, en el bajo número de habitantes; así, examinando las diferentes tasas de función en relación al tipo de alojamiento, se puede decir que el número de plazas en tiendas de campaña es suficiente y con ellas se alcanza una tasa de plena función turística, pero dada el área montañosa donde nos encontramos, con problemas climatológicos en algunas épocas del año, será preciso utilizar otro tipo de alojamiento, sea hotelero, residencial, etc. $Y$ es aquí donde, para completar la oferta de alojamientos y con la finalidad de que todos los municipios alcancen una tasa más próxima a 100, cabe la posibilidad de ampliar la oferta de viviendas rurales hasta las doscientas, consiguiendo así una tasa de función turística aceptable sin ser desmedida, máximo cuando el modelo de turismo agrorural se caracteriza por la dispersión de las viviendas dedicadas al efecto a la vez que se encuentran ya integradas en el espacio urbanísticamente considerado.

Podemos decir, pues, que con el número de plazas existentes la capacidad de acogida está próxima a los límites adecuados, faltaría solamente aumentar el número de plazas de vivienda rural para que exista un mayor equilibrio entre la oferta de inmueble y la oferta en tienda, haciendo subir la tasa citada de 83'6 hasta un nivel más "turístico".

¿Por qué viviendas de turismo rural? Por varias razones, algunas ya esbozadas anteriormente. La primera, medio ambiental, ya que es una alternativa abierta, artesanal, integrada en el espacio natural y social; la segunda razón es la posibilidad de implantarse bien y rápidamente. No se trata de una invención, sino más bien de una innovación. De una forma u otra ya se venía prestando un mínimo de servicios de tipo turístico. Hay que decir además, que no es una fórmula sustitutoria, sino compatible, con la actividad tradicional; la población muy aferrada a sus costumbres, no hace tabla rasa de sus actividades anteriores y por lo tanto tiene una mayor predisposición. Es sencillo y fácil de experimentar dado que no requiere una fuerte inversión y ésta se ve favorecida por la Administración con una serie de ayudas económicas y préstamos a reducido interés. A todo lo anterior hay que añadir que los resultados, la mayoría observables, se difunden enseguida, siendo además positivos por cuanto llegan a las 
economías familiares beneficios económicos y se crea un vehículo de comunicación directa entre personas con mentalidades antagónicas, la rural y la urbana. Respecto a la difusión de esta modalidad sólo cabe aportar un dato, en 1990 el número de habitaciones era de 57 en el Alto Sobrarbe Oriental habiendo pasado en el año 1993 a 130, destacando sobremanera el incremento en Escalona perteneciente al municipio de Puértolas, y Gistaín y San Juan de Plan en la "bal de Chistau".

En cualquier caso, apostamos decididamente por esta fórmula de turismo en casas de agricultores como ya hicieran hace años países como Austria, Suiza o la vecina Francia, con resultados altamente satisfactorios, pero conocedores de la fragilidad del medio ante cualquier acción incontrolada por parte de un ser humano, exigimos igualmente un marco legal amplio y a la vez concreto que pueda poner coto a las posibles agresiones al medio natural.

Son muchas las propuestas a esgrimir para que ese equilibrio sostenible que se busca se consiga y tenga una estabilidad en el tiempo. Hace falta planificar desde una depuración de las aguas a un servicio sanitario o una gestión y organización adecuadas de la implantación y desarrollo del modelo agroturístico. Con todo, lo importante es tener un proyecto de futuro y después ir trabajando por conseguirlo y mejorarlo.

En resumen, es posible y conveniente la implantación del turismo rural en el Sobrarbe. Como ventajas cabría destacar entre otras, las siguientes: un entorno de calidad, un paisaje privilegiado y una situación geográfica envidiable, en la isocrona de 150' respecto a metrópolis regionales como Zaragoza o Toulouse, 180' Barcelona, o en la isocrona 100' respecto a las capitales provinciales de Huesca, Lérida o departamentales, Tarbes.

En el apartado de inconvenientes es preciso reseñar la escasa población de derecho y de hecho, lo que incide en un tejido social débil y por tanto la necesidad de que el número de visitantes no sea muy numeroso, de lo contrario la sociedad montañesa se vería absorbida por los turistas. Por otro lado, dada la dispersión de los alojamientos rurales, el peligro de invasión y aglomeración disminuye, de forma que vistos los pros y los contras estamos en condiciones de afirmar que el turismo rural puede ser la actividad que genere unos ingresos supletorios a las economías familiares. La experiencia en otros lugares es muy positiva. Por parte de la Diputación de Teruel según zonas y precios el aporte oscila entre un 20-30\% de la renta. Esto incide a la vez en la implantación de otras actividades fundamentalmente terciarias, de servicios, recreo, etc. aumentando las posibilidades de vivir en la comarca.

Los pueblos del Sobrarbe pueden pasar del abandono y la desolación a su rehabilitación patrimonial y social, convirtiéndose en pueblos vivos con una funcionalidad turística importante, verdaderos pueblos turísticos plenamente 
insertados en el medio natural y con unos entramados sociales cada vez más regenerados fruto de un aumento de las relaciones entre las personas que allí viven y las que acudan, aunque sólo sea temporalmente. Las nuevas tendencias y actividades laborales en el medio rural, ya sean turísticas o ambientales, o como meros vigilantes o jardineros del gran recurso natural que es la montaña, ya sean actividades de servicios o ganaderas, van a hacer que el montañés encuentre un medio de vida en el lugar que le vio nacer.

\section{BIBLIOGRAFIA}

AGANZO, A. (1989): "El turismo en el espacio rural". La acción social, 19, Cáritas, Madrid, 47 p.

BIELZA DE ORY, V. (1989): Sociedad y Territorio en España, Tomo I. Ed. Taurus, Madrid.

BOTE GOMEZ, V. (1988): Turismo en espacio rural. Ed. Popular, Madrid, 134 p.

BOSQUE SENDRA, J. et al. (1992): Prácticas de Geografúa de la Percepción y de la actividad cotidiana. Ed. Oikos-Tau, Barcelona, 138 p.

BOULLON, R. (1984): Un nuevo tiempo libre. Ed. Trillas, Méjico, 80 p.

CALLIZO SONEIRO, J. (1991): Aproximación a la geografía del turismo. Ed. Síntesis, Col. Geografía, 21, Madrid, 215 p.

DE KADT, E. (1991): Turismo ¿pasaporte al desarrollo? Endymion, Madrid, 495 p.

DIAN ALVAREZ, J. (1988): Geografía del turismo. Ed. Síntesis, Col. Geografía, 12, Madrid, 157 p.

GARCIA BALLESTEROS, A. (1992): Geografía y Humanismo. Ed. Oikos-Tau, Barcelona, 114 p.

JURDAO, F. (1992): Los mitos del turismo. Endymion, Madrid, 403 p.

LABASSE, J. (1973): La organización del espacio. I.E.A.L., Madrid, 735 p.

LANQUAR, R. (1991): La economía del turismo. Oikos-Tau, Col, ¿Qué sé?, 171, Barcelona.

LOZATO GIOTAR, J.P. (1987): Géographie du tourisme. Ed. Masson, Paris, 190 p.

NOVO VILLAVERDE, M. (1985): Educación Ambiental. Ed. Anaya, Madrid, 197 p. 
NOVO VILLAVERDE, M. (1986): Educación y Medio Ambiente. Cuadernos de la UNED, Madrid, $112 \mathrm{p}$.

SESSA, A. (1989): La science des systemes pour les plans regionaux de developpement touristique. Centre des Hautes Etudes Touristiques, Aix-en-Provence, 41 p.

SMITH, V. (1989): Anfitriones e invitados. Endymion, Madrid, 481 p.

VILLANUEVA ZARAZAGA, J. (1991): Sustitución del sistema agrario tradicional por actividades modernas en el Alto Sobrarbe Oriental: el turismo. Memoria de Licenciatura, Universidad de Zaragoza, Zaragoza, $271 \mathrm{p}$. 